\title{
Fusion expression of nanobodies specific for the insecticide fipronil on magnetosomes in Magnetospirillum gryphiswaldense MSR-1
}

Sha $\mathrm{Wu}^{1,2}$, Fengfei $\mathrm{Ma}^{1,2}$, Jinxin $\mathrm{He}^{1,2}$, Qing X. $\mathrm{Li}^{3}$, Bruce D. Hammock ${ }^{4}$, Jiesheng Tian ${ }^{5^{*}}$ and Ting $\mathrm{Xu}^{1,2^{*}}$ (1)

\begin{abstract}
Background: Magnetic nanoparticles such as magnetosomes modified with antibodies allow a high probability of their interaction with targets of interest. Magnetosomes biomineralized by magnetotactic bacteria are in homogeneous nanoscale size and have crystallographic structure, and high thermal and colloidal stability. Camelidae derived nanobodies (Nbs) are small in size, thermal stable, highly water soluble, easy to produce, and fusible with magnetosomes. We aimed to functionalize Nb-magnetosomes for the analysis of the insecticide fipronil.
\end{abstract}

Results: Three recombinant magnetotactic bacteria (CF, CF+, and CFFF) biomineralizing magnetosomes with different abundance of $\mathrm{Nbs}$ displayed on the surface were constructed. Compared to magnetosomes from the wild type Magnetospirillum gryphiswaldense MSR-1, all of the Nb-magnetosomes biosynthesized by strains CF, CF+, and CFFF showed a detectable level of binding capability to fipronil-horseradish peroxidase (H2-HRP), but none of them recognized free fipronil. The $\mathrm{Nb}$-magnetosomes from CFFF were oxidized with $\mathrm{H}_{2} \mathrm{O}_{2}$ or a glutathione mixture consisting of reduced glutathione and oxidized glutathione in vitro and their binding affinity to H2-HRP was decreased, whereas that to free fipronil was enhanced. The magnetosomes treated with the glutathione mixture were employed to develop an enzyme-linked immunosorbent assay for the detection of fipronil in water samples, with average recoveries in a range of $78-101 \%$.

Conclusions: The economical and environmental-friendly $\mathrm{Nb}$-magnetosomes biomineralized by the bacterial strain MSR-1 can be potentially applied to nanobody-based immunoassays for the detection of fipronil or nanobody-based assays in general.

Keywords: Magnetosome, Magnetospirillum gryphiswaldense, Nanobody, Fipronil, Immunoassay

\section{Background}

Magnetic nanoparticles (MNPs) have been extensively applied in the life sciences due to their multiple attributes such as large surface-area-to-volume ratio, biocompatibility and simple separation methodology $[1,2]$.

\footnotetext{
*Correspondence: tianhome@cau.edu.cn; xuting@cau.edu.cn

${ }^{1}$ Beijing Key Laboratory of Biodiversity and Organic Farming, College

of Resources and Environmental Sciences, China Agricultural University, Beijing 100193, China

${ }^{5}$ Department of Microbiology, College of Biological Sciences, China Agricultural University, Beijing 100193, China

Full list of author information is available at the end of the article
}

Magnetite $\left(\mathrm{Fe}_{3} \mathrm{O}_{4}\right)$, one of the magnetic materials widely used in MNPs, are usually produced by co-precipitation as the simplest and most economical method [3]. A variety of coating materials (e.g., chitosan) of MNP surfaces have been used to reduce the aggregation of particles, preserve their stability and facilitate their further functionalization with biomolecules $[4,5]$.

In contrast to MNPs produced by a physical-chemical reaction, magnetosomes are biomineralized by magnetotactic bacteria (MTB), a phylogenetically and physiologically diverse group of prokaryotes [6]. Magnetosomes 
consisting of magnetite materials $\left(\mathrm{Fe}_{3} \mathrm{O}_{4}\right)$ covered by a bilayer membrane with numerous specific proteins have advantages over other MNPs for their homogeneous sizes and crystallography as well as high thermal and colloidal stability [7, 8]. Magnetosomes functionalized with genetic or chemical methods have gained considerable interest in a broad range of applications, such as immunoassays, biosensor, drug delivery and biomedical imaging [8]. Because of their cost-effective and environmental-friendly nature, genetic modifications to functionalize magnetosomes have been an important research topic. Many of the proteins in magnetosome membranes have been studied to uncover their roles in magnetosome biomineralization $[7,9]$. This fundamental knowledge has been used to modify magnetosomes [8, 10]. MamC and MamF are acknowledged as two of the most abundant proteins in magnetosome membrane. They are relatively small proteins $(\sim 12.5 \mathrm{kD})$ with two or three predicted transmembrane helices associated tightly with the magnetosome membrane [9]. mamC and mamF are both in the mamGFDC operon of Magnetospirillum gryphiswaldense MSR-1, and have a minor and nonessential function in magnetite biomineralization [11]. Thus, MamC and MamF have been frequently exploited for the magnetosomal display of functional proteins such as immunoglobulin G-binding domains [12], thyroid-stimulating hormone receptor (TSHR) [13] and Staphylococcal protein A (SPA) [14].

The variable domain of Camelidae heavy-chain-only antibodies (VHHs), also referred to as nanobodies (Nbs), have superior properties to conventional antibodies for their small size, non-immunogenicity, thermal stability, high solubility, ease of production in microorganisms and ease of genetic modification $[15,16]$. The extensive availability of molecular biological techniques facilitates the genetic conjugation of Nbs to magnetosomes, but only one investigation on the fusion expression of $\mathrm{Nbs}$ binding red fluorescent protein (RFP) on magnetosomes has been reported so far [17]. Over the past few years, Nbs are attractive in the field of immunoassays for monitoring small molecules such as biomarkers and environmental pollutants [18]. Nbs chemically conjugated to magnetosomes proved to be an effective tool for the detection of environmental compounds [19,20]. It is promising to display nanobodies on magnetosomes by a genetic method to monitor small-molecule contaminants.

In our previous study, Nbs selective to fipronil and its metabolites were generated and used for the detection of fipronil in rodent sera [21]. Fipronil is the first phenylpyrazole insecticide that acts at the $\gamma$-aminobutyric acid (GABA) receptor of insects, blocking the passage of chloride ions [22]. It is widely used for the control of field insects in agriculture as well as fleas and ticks on pets [23]. Nevertheless, the widespread use of fipronil has induced an increasing concern about the possible offtarget harm to ecosystems and human health particularly when employed in non approved application [24].

Here, we displayed a $\mathrm{Nb}$ (F1) on magnetosomes by gene fusion using MamC and MamF as anchoring proteins in MSR-1. MSR-1 gives the highest magnetosome yields among the MTB [25], to construct functional MNPs specific for fipronil. The modified magnetosomes could be easily produced with low cost, having a potential application in the field of immunoassays.

\section{Methods and materials}

\section{Bacteria strains and culture conditions}

The bacteria strains and plasmids used in this study are listed in Additional file 1: Table S1. Escherichia coli strains were cultured in Luria broth (LB) at $37^{\circ} \mathrm{C}$. MSR-1 was cultured in sodium lactate medium (SLM) or sodium glutamate medium (SGM) (substitute $4 \mathrm{~g}$ sodium glutamate for $\mathrm{NH}_{4} \mathrm{Cl}$ and yeast extract in SLM) as described previously [26]. Large-scale MSR-1 cells were fed-batch cultured in a $7.5 \mathrm{~L}$-fermenter according to the method reported by Zhang et al. [27]. Antibiotics prepared in culture media were as follows: for $E$. coli, ampicillin at $100 \mu \mathrm{g} / \mathrm{mL}$ and kanamycin at $50 \mu \mathrm{g} / \mathrm{mL}$; for MSR-1, kanamycin at $5 \mu \mathrm{g} / \mathrm{mL}$ and nalidixic acid at $5 \mu \mathrm{g} / \mathrm{mL}$. The growth of MSR-1 $\left(\mathrm{OD}_{565}\right)$ and the response to a magnet field (Cmag) were detected according to the methods described previously [28].

\section{Construction of recombinant plasmids and strains}

All primers used in this study are listed in Additional file 1: Table S2. The restriction enzyme digestion (TaKaRa, Japan), DNA ligation (TaKaRa, Japan), and polymerase chain reaction (PCR) (Vazyme, China) were conducted according to manufacturers' instructions. $m a m C$ and $m a m F$, along with their upstream and downstream flanking sequences, were amplified from MSR-1 genomic DNA. The anti-fipronil $\mathrm{Nb}$ gene was amplified from $\mathrm{Nb} F 1$ encoded in the pComb 3X vector [21]. uCFd, a cassette consisting of mamC upstream region, $\operatorname{mamC}$, $\mathrm{Nb}$ gene, and mam $C$ downstream region, and $\mathrm{uFFd}$, a cassette consisting of $m a m F$ upstream region, $m a m F, \mathrm{Nb}$ gene, and $m a m F$ downstream region, were assembled by fusing PCR amplification. uCFd and uFFd were then subcloned into pK18mobSacB digested with EcoR I and Xba I to construct the suicide recombinant plasmids $\mathrm{pKCF}$ and pKFF, respectively. CF, a fusion gene consisting of $\operatorname{mamC}$ and $\mathrm{Nb}$ gene, was amplified from uCFd with primers MamC-F (EcoR I) and Fip-R (Xba I), and subcloned into pBBR1MCS-2 to create pBBRCF.

pKCF was transferred to wild type (WT) MSR-1 to generate a double crossover strain $\mathrm{CF}$, which was 
successively cultured in medium containing kanamycin and $10 \%$ sucrose. pKFF and pBBRCF were then transferred to the strain CF to generate CFFF and CF+, respectively. Strains $\mathrm{CF}+$ and CFFF were cultured in medium containing kanamycin.

\section{Extraction of Nb-magnetosomes}

Cells were harvested by centrifugation $(8000 \times g)$. Approximately $1 \mathrm{~g}$ cell pellets were suspended in $40 \mathrm{~mL}$ of PBS (0.01 M phosphate, $0.137 \mathrm{M} \mathrm{NaCl}$, and $0.003 \mathrm{M} \mathrm{KCl}, \mathrm{pH}$ 7.4), which was prepared with ultrapure water and then autoclaved to denature protease and reduce the concentration of dissolved oxygen $\left(\mathrm{dO}_{2}\right)$. The cells were ultrasonically disrupted under a power of $200 \mathrm{~W}$ for $30 \mathrm{~min}$ (work $3 \mathrm{~s}$, stop $5 \mathrm{~s}$ every cycle), next to $100 \mathrm{~W}$ and $60 \mathrm{~W}$ in turn. The suspension of broken cells was placed in a magnetic field for $3.5 \mathrm{~h}$ to separate $\mathrm{Nb}$-magnetosomes from solution. Precipitates were resuspended in PBS and washed ultrasonically $(40 \mathrm{~W})$ for about $30 \mathrm{~min}$, followed by separation with magnetism. The suspend-wash-separate step was repeated until $\mathrm{OD}_{260} / \mathrm{OD}_{280}$ of supernatant proteins was unchanged. The extraction workflow is shown in Additional file 1: Fig. S1.

\section{Treatment of $\mathrm{Nb}$-magnetosomes with oxidants}

$\mathrm{Nb}$-magnetosomes were treated with $\mathrm{H}_{2} \mathrm{O}_{2}$ solution $(0.1-10 \%)$ or a mixture of reduced glutathione (GSH) and oxidized glutathione (GSSG) with different ratios (20:1, 10:1, 5:1, and 2:1). The treating time was $0.5,1,3$, and $5 \mathrm{~h}$.

\section{Couple of fipronil derivative to enzyme}

The hapten (H2) (Additional file 1: Fig. S2) of fipronil was available from our previous study [21] and coupled to horseradish peroxidase (HRP) according to the method reported by Schneider and Hammock [29]. The concentrations of $\mathrm{H} 2-\mathrm{HRP}$ were determined with $\mathrm{BCA}$ protein assay.

\section{$\mathrm{Nb}$-Magnetosome-based immunoassays for fipronil}

Magnetosome-based enzyme-linked immunosorbent assays (ELISAs) for the analysis of small molecules were available from previous studies $[19,20]$. Briefly, a 96-well microtiter plate was blocked with $1 \%$ gelatin dissolved in carbonate-bicarbonate buffer ( $\mathrm{pH}$ 9.6) (300 $\mu \mathrm{L}$ per well) at $4{ }^{\circ} \mathrm{C}$ overnight, followed by washing with PBST (PBS containing $0.05 \%$ Tween-20) three times. Nb-magnetosomes were blocked with $2 \%$ bovine serum albumin (BSA) in PBS at room temperature for $3 \mathrm{~h}$ and washed with PBST. Afterwards, an aliquot volume of Nb-magnetosomes were transferred to the blocked microtiter plate. The solutions of fipronil and H2-HRP, each at $50 \mu \mathrm{L}$, were successively added into wells harboring $\mathrm{Nb}$-magnetosomes, and the plate was incubated on an oscillator
$(150 \mathrm{rpm} / \mathrm{min})$ at room temperature for $1 \mathrm{~h}$. The plate was then fastened on a magnetic frame and washed with PBST. A $100-\mu \mathrm{L}$ aliquot of 3,3',5,5'-tetramethylbenzidine (TMB) solution ( $400 \mu \mathrm{L}$ of $0.6 \%$ TMB and $100 \mu \mathrm{L}$ of $1 \%$ $\mathrm{H}_{2} \mathrm{O}_{2}$ in $25 \mathrm{~mL}$ of citrate buffer, $\mathrm{pH}$ 5.5) was added into the wells and the reaction was stopped 10 min later by adding $50 \mu \mathrm{L}$ of $\mathrm{H}_{2} \mathrm{SO}_{4}(2 \mathrm{M})$. Finally, the mixture was read at $450 \mathrm{~nm}$ on a microtiter plate reader (ELx800, Bio Tek, USA).

The resulting ELISA was applied to the analysis of fipronil in water samples which were collected from Lake Kunming in Beijing, China. Water samples were fortified with fipronil to reach the final concentrations of 100, 150, and $200 \mathrm{ng} / \mathrm{mL}$. These samples were passed through a $0.22-\mu \mathrm{m}$ filter (Waters, MA, USA) and then diluted with PBS (pH 7.4) prior to magnetosome-based ELISAs.

\section{Results}

\section{Construction of recombinant strains to biomineralize Nb-magnetosomes}

MamC and MamF were selected as anchor proteins to engineer with anti-fipronil $\mathrm{Nbs}$ because they have high abundance in the membrane of the magnetosome from MSR-1 and negligible influence on the biomineralization of magnetosomes [9, 11]. In order to obtain $\mathrm{Nb}$-magnetosomes possessing desirable affinity to fipronil, three recombinant strains that could biosynthesize magnetosomes with varying abundance of Nbs were constructed. The procedure of strain construction is shown in Fig. 1a.

Because $s a c B$, a gene from Bacillus subtilis, encodes levansucrase coverting sucrose to levans, lethal to many Gram-negative bacteria (e.g., Desulfovibrio magneticus RS-1) [30], it is commonly used as a counterselection marker. A suicide vector, carrying a selectable marker flanked by upstream and downstream regions of homology to a host target gene, could be integrated into the chromosomes of hosts. The suicide vector pK18mobSacB has two features: (i) neo conferring resistances to neomycin and kanamycin can be used to confirm integration events at the designated site of genome; (ii) $s a c B$ assists in obtaining the desired mutant strains by preserving the target gene left in genome but excising its vector backbone from genome. In this way, the mutant strains can be further modified by inserting another pK18mobSacB or other plasmids. In the present study, pKCF carrying the gene cassette $\mathrm{uCFd}$ expressing the anti-fipronil $\mathrm{Nb}$ at the C-terminal of MamC was transferred into WT MSR-1 (Additional file 1: Tables S1 and S2) to generate a double crossover mutant strain, named as $\mathrm{CF}$, which was successively identified by colony PCR (Fig. 1b) and gene sequencing. However, CF has only one copy of $\mathrm{Nb} F 1$ gene in its genome so that the expression of $\mathrm{Nbs}$ may be limited [31]. To increase the abundance of Nbs 
displaying on magnetosomes, a multi-copy broad host range vector pBBR1MCS-2 carrying a fusion gene CF expressing $\mathrm{Nbs}$ at the $\mathrm{C}$-terminal of MamC, named as pBBRCF, was transferred into the mutant strain CF, generating $\mathrm{CF}+$ with multi-copy $\mathrm{Nb} \mathrm{F} 1$ gene, i.e., $\mathrm{CF}$ strain harbored plasmid pBBRCF in cytoplasm (Additional file 1: Table S1). In addition, a suicide vector pK18mob$\mathrm{SacB}$ carrying a gene cassette $\mathrm{uFFd}$ expressing $\mathrm{Nbs}$ at the C-terminal of MamF, named as pKFF, was conjugated to the mutant strain CF, generating CFFF with two copies of Nb F1 genes in MSR-1 genome, i.e., pKFF was integrated into CF strains' chromosomes (Additional file 1: Table S2). Both CF+ and CFFF were identified via gene sequencing and colony PCR (Fig. 1c, d).

\section{Magnetic response of recombinant strains in fed-batch culture fermentation}

Each of the recombinant strains (CF, CF+, and CFFF) was propagated three times (10\% inoculation) in SLM supplemented with $20 \mu \mathrm{M}$ ferric citrate, and then submerged in a 7.5-L fermenter for fed-batch culture. The lag phase of growth curves $\left(\mathrm{OD}_{565}\right)$ from $\mathrm{CF}+$ and $\mathrm{CFFF}$ was longer than that from CF (Fig. 2), suggesting that the growth and magnetosome biomineralization of strains would be restrained by transferring $\mathrm{pBBRCF}$ and $\mathrm{pKFF}$ into CF.

Cmag values were calculated by measuring the maximum and minimum scattering intensities [32]. A typical parabolic curve of Cmag values was observed from the strain CF (Fig. 2a), but the curves of Cmag values from $\mathrm{CF}+$ and CFFF could be divided into two parts: a decreasing curve and a parabolic curve (Fig. 2b, c). It is well known that MSR-1 biosynthesizes magnetosomes under low oxygen conditions $\left(\mathrm{dO}_{2}<1 \%\right)$. When cells were transferred into the fermenter, $\mathrm{dO}_{2}$ of the culture medium was high and the biomineralization of magnetosomes in cells was temporarily inhibited, leading to the initial decrease of Cmag from CF+ and CFFF. Nonetheless, CF grew faster than $\mathrm{CF}+$ and $\mathrm{CFFF}$, and $\mathrm{dO}_{2}$ could be quickly driven down to a concentration suitable for the biomineralization of magnetosomes in CF after the transfer. Therefore, the initial decrease curve of Cmag was not observed from CF. After the culture of CF, CF+ and CFFF for 22, 36, and $48 \mathrm{~h}$, respectively, Cmag values declined steadily, illustrating that $\mathrm{dO}_{2}$ was enhanced with the increase of stirring rate. In general, the cells should be harvested before Cmag values dropped dramatically to ensure a sufficient yield of $\mathrm{Nb}$-magnetosomes. Hence, when the Cmag values of $\mathrm{CF}, \mathrm{CF}+$, and CFFF moved down to approximately 1.0 from the peak, cells were harvested even though they were still in the exponential phase of growth.

\section{Characteristics of $\mathrm{Nb}$-magnetosomes}

$\mathrm{Nb}$-magnetosomes were extracted and purified ultrasonically under different power (Additional file 1: Fig. $\mathrm{S} 1)$. As the concentration of proteins in the supernatant $\left(\mathrm{OD}_{260} / \mathrm{OD}_{280}\right)$ was constant, the purification procedure was stopped to avoid the damage of magnetosome membranes.

$\mathrm{Nb}$-magnetosomes synthesized by $\mathrm{CF}, \mathrm{CF}+$, and CFFF exhibited different binding capability to $\mathrm{H} 2-\mathrm{HRP}$ in a non-competitive ELISA, with the highest $\mathrm{OD}_{450}$ from CFFF (Fig. 3a). Compared to CF, CFFF with a suicide vector $\mathrm{pKFF}$ integrated into chromosomes probably expressed more Nbs on the surface of magnetosomes, but $\mathrm{CF}+$ with a plasmid pBBRCF in cytoplasm did not show more $\mathrm{Nb}$ expression as expected. It was reported that in the construction of a complementary strain, gene copies, promoters, and regulatory processes were distinctive in plasmid vs genome structure, causing the difference of transcription and expression levels [33]. Unfortunately, none of the Nb-magnetosomes exhibited binding ability to fipronil at $1000 \mathrm{ng} / \mathrm{mL}$ in a competitive ELISA (Fig. 3b-d), suggesting that the binding affinity of Nbs to H2-HRP was much stronger than that to fipronil. Since the Nb-magnetosomes from CFFF had the highest binding capability to H2-HRP, they were used for the following studies on the improvement of binding ability to free fipronil.

\section{Treatment of $\mathrm{Nb}$-magnetosomes with oxidants}

Two disulfide bonds might stabilize the three-dimensional structure of the anti-fipronil $\mathrm{Nb} F 1$ due to four cysteines existing in the amino acid sequence (Additional file 1: Fig. S3). The formation of disulfide bonds is an oxidative process. Anti-fipronil Nb F1 could, however, be expressed in E. coli ER2738 or Top 10F' with reductive cytoplasms, and they showed high binding capability to fipronil [21]. Nb-magnetosomes were also biomineralized in the reductive cytoplasm media of MSR-1. The failure of $\mathrm{Nb}$-magnetosomes to recognize fipronil may have resulted from the incorrect formation of intramolecular disulfide bonds in a reductive environment in vivo. Oxidation and reduction of disulfide bonds were reported to be an effective means to activate functional proteins in vitro [34, 35]. To improve the binding capability to fipronil, Nb-magnetosomes biomineralized by CFFF were oxidized by $\mathrm{H}_{2} \mathrm{O}_{2}$ (Fig. 4a) or glutathione mixture (GSH and GSSG) in vitro (Fig. 4b). The optimized concentration of $\mathrm{H}_{2} \mathrm{O}_{2}$ was $2 \%$ and the optimal ratio of GSH: GSSG in glutathione mixture was 10:1, i.e., the concentrations of GSH and GSSG were $1.0 \times 10^{-3} \mathrm{M}$ and 


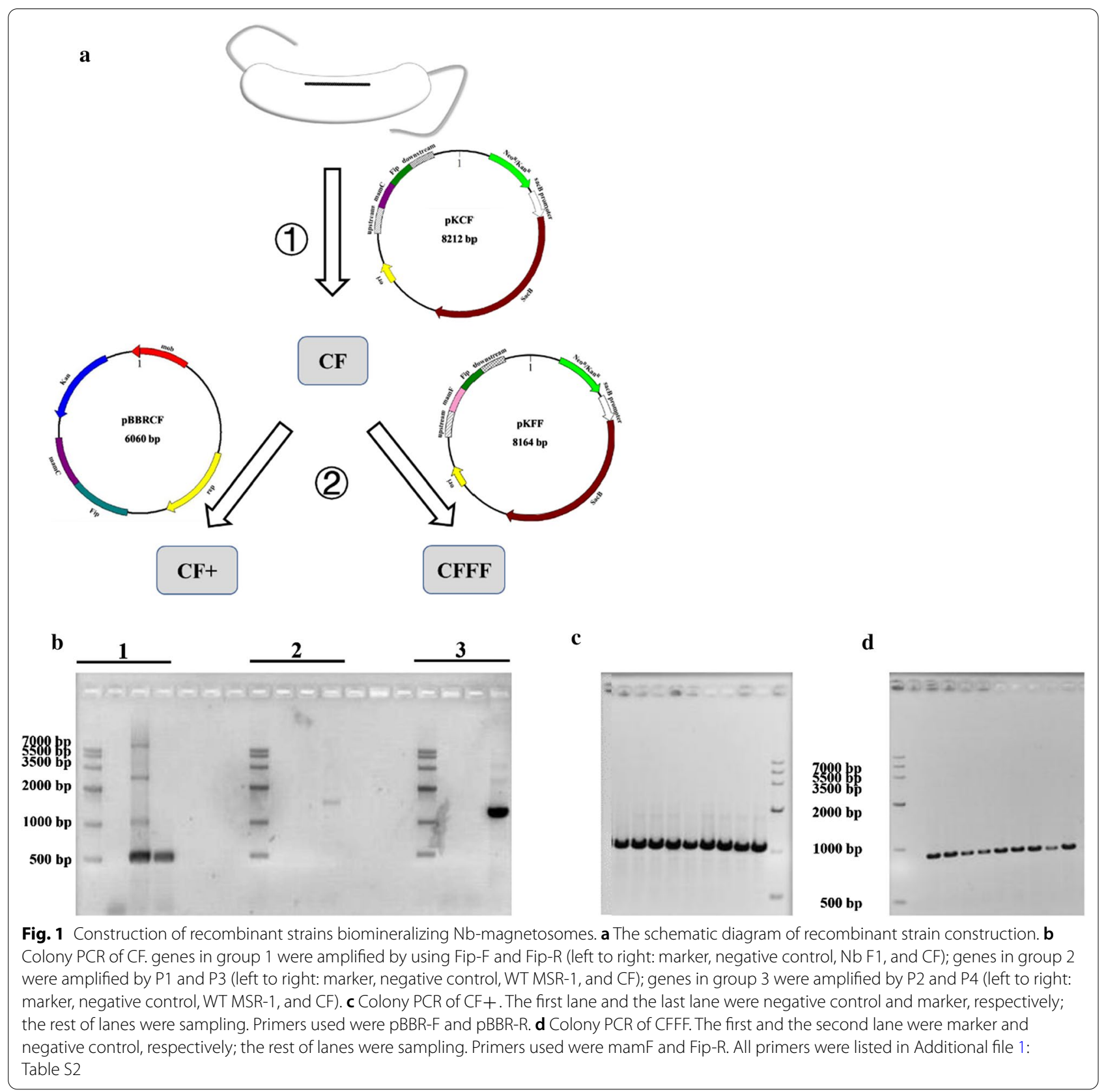

$1.0 \times 10^{-4} \mathrm{M}$, respectively. The time treated by $\mathrm{H}_{2} \mathrm{O}_{2}$ and glutathione mixture was 5 and $2 \mathrm{~h}$, respectively.

The binding ability of Nb-magnetosomes to H2-HRP was weakened after oxidation, which the $\mathrm{OD}_{450}$ values were lower than those before oxidation. In addition, the $\mathrm{OD}_{450}$ was lowered upon $\mathrm{H}_{2} \mathrm{O}_{2}$ treatment (GSH vs GSSG) (Fig. 4). It is noteworthy that the binding capability of all oxidized $\mathrm{Nb}$-magnetosomes to $\mathrm{H} 2-\mathrm{HRP}$ was inhibited in the presence of free fipronil $(1000 \mathrm{ng} / \mathrm{mL})$. The maximum inhibition was approximately $40 \%$ from the $\mathrm{Nb}$-magnetosomes $(145 \mu \mathrm{g})$ treated by two oxidants.
One of the possible reasons is that after Nb-magnetosomes have been oxidized, the net charge on the nanobodies has changed and disturbed the electrostatic interactions between $\mathrm{Nbs}$ and the complex H2-HRP, indirectly improving the binding affinity to fipronil on which the net charge became more suitable for electrostatic interaction. This result is consistent with that of other studies on the modification of protein function via disulfide bond formation in vitro $[35,36]$. 

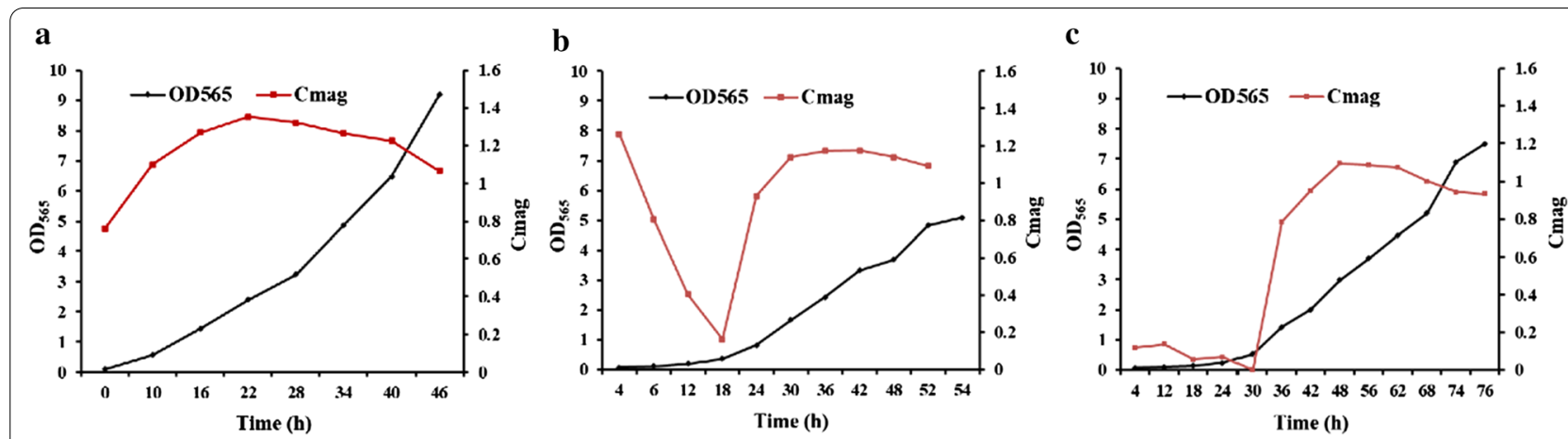

Fig. 2 The growth $\left(\mathrm{OD}_{565}\right)$ and magnetic response (Cmag values) curves of $\mathrm{CF}(\mathbf{a}), \mathrm{CF}+(\mathbf{b})$ and $\mathrm{CFFF}$ (c) fed-batch cultured in a fermenter

\section{Analysis of fipronil in water by ELISA}

The analysis of fipronil by the $\mathrm{Nb}$-magnetosome-based ELISA was optimized and a dose-response curve was generated in $0.01 \mathrm{M} \mathrm{PBS}$ ( $\mathrm{pH}$ 7.4) (Fig. 5), showing a half-maximum signal inhibition concentration $\left(\mathrm{IC}_{50}\right)$ and a limit of detection (LOD, $\mathrm{IC}_{10}$ ) of fipronil at $47 \mathrm{ng} /$ $\mathrm{mL}$ and $2.74 \mathrm{ng} / \mathrm{mL}$, respectively. Slight matrix effect of water samples on the assay was observed, but it could be eliminated via sample dilution with PBS at twofold or more than twofold (data not shown). The average recoveries of fipronil from the fortified water samples as determined with ELISAs were in a range of $78-101 \%$ (Table 1), illustrating a promise of the oxidized Nbmagnetosomes in immunoassay development for the detection of fipronil in real samples.

\section{Discussion}

In MTB, approximately 30 specific proteins in the membrane of magnetosomes have been identified so far [7, 9]. Among those proteins, the most abundant one is MamC,
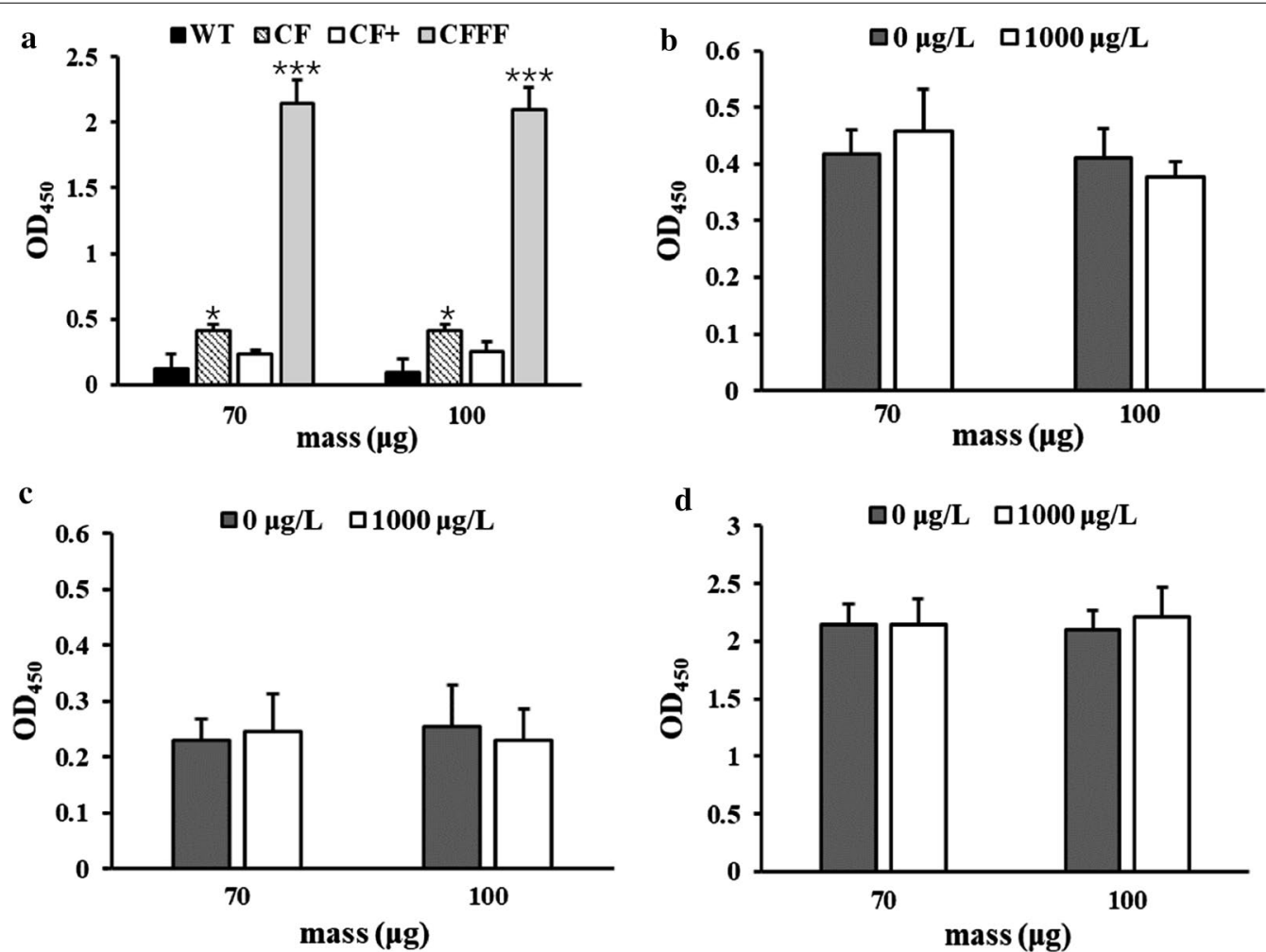

Fig. 3 Non-competitive ELISAs based on three Nb-magnetosomes (a) and competitive ELISAs for fipronil based on Nb-magnetosomes from CF (b);

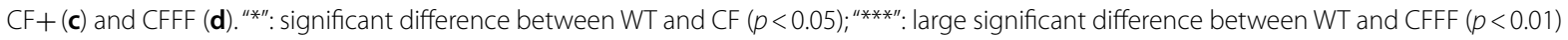



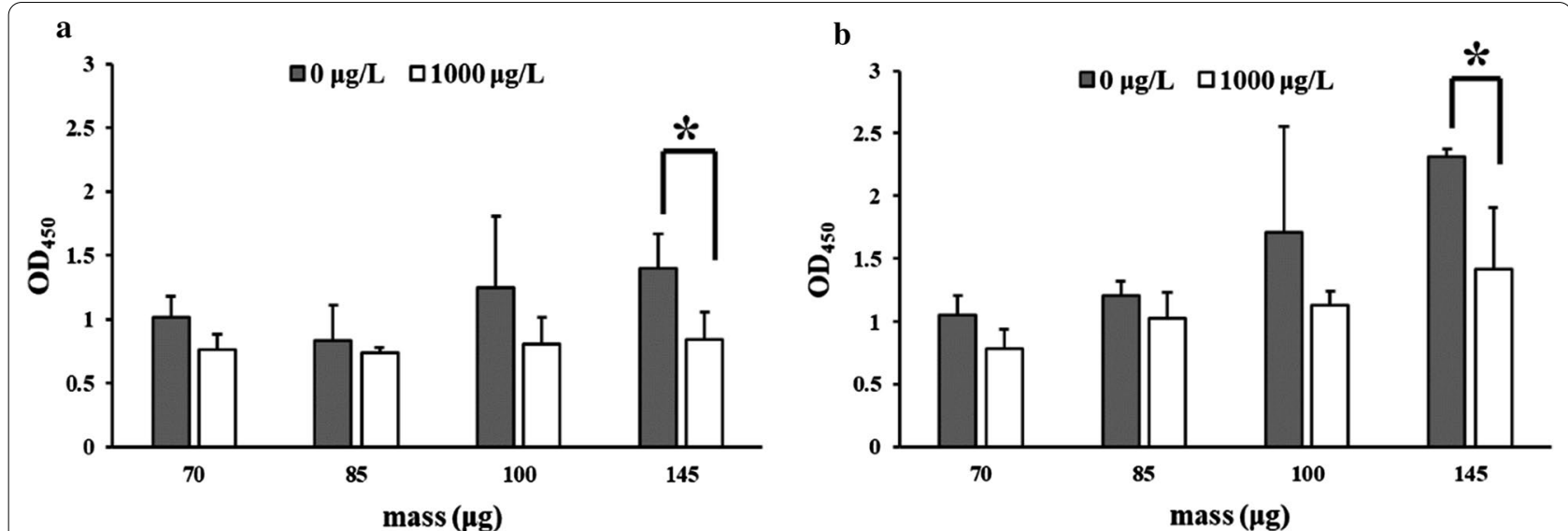

Fig. 4 Competitive ELISAs for fipronil using Nb-magnetosomes treated with $\mathrm{H}_{2} \mathrm{O}_{2}$ (a) or a mixture of GSH and GSSG (b). " *": significant difference $(p<0.05)$

followed by MamF. Nbs can be anchored on magnetosomes by genetically fusing to one or more specific membrane proteins. An alpaca-derived Nb specific for RFP was fused with MamC to construct a complex of $\mathrm{Nb}$-magnetosomes, which was used for the immunoprecipitation of RFPtagged proteins from cell extracts [17]. The three-dimensionality and the high surface-area-to-volume ratio of antibody modified MNPs allowed a relatively high probability of their interaction with targets. Hence, we fused antifipronil Nbs with MamC and MamF on magnetosomes for their potential application in various immuno-techniques.

$\mathrm{CF}$ was initially constructed by inserting $\mathrm{Nb} \mathrm{F} 1$ gene into the genome of WT MSR-1, but only low amounts of Nbs were expressed. Then, strain $\mathrm{CF}+$ containing multicopy F1 genes and strain CFFF with two copy F1 genes were constructed in an attempt to enhance $\mathrm{Nb}$ abundances on magnetosomes. For the construction of $\mathrm{CF}+$, a multi-copy broad host range plasmid pBBRCF containing CF gene was transferred into cytoplasm of CF strain. For

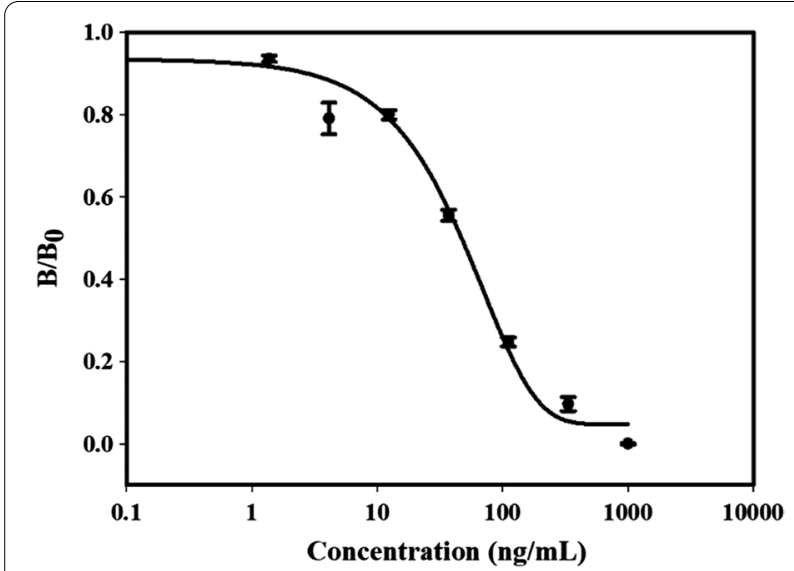

Fig. 5 Calibration curve of Nb-magnetosome-based ELISA for fipronil. The data are average of three replicates
CFFF, the suicide plasmid pKFF containing uFFd gene was integrated into the genome of CF strain. Theoretically, the Nbs displayed on magnetosomes from CFFF containing two copies of $\mathrm{Nb}$ gene in genome and $\mathrm{CF}+$ containing one copy of $\mathrm{Nb}$ gene in genome and another in multicopies of pBBR1MCS-2 were more than those from CF which has only one copy of $\mathrm{Nb}$ gene in genome. However, $\mathrm{Nb}$-magnetosomes biomineralized by the recombinant strains showed different binding capability to H2-HRP in a declining order of CFFF, CF, and CF+ (Fig. 3a). The possible reason is that the expression of genes in the plasmid of $\mathrm{CF}+$ was restricted, leading to the least binding affinity of $\mathrm{Nb}$-magnetosomes from $\mathrm{CF}+$. The restriction of gene expression in plasmids is not rare, e.g., the construction of a complementary strain with the help of pBBR1MCS-2 was not successful [33].

The formation of disulfide bonds is an oxidative process that generates a covalent bond from two cysteine residues, greatly increasing the stability of proteins (Additional file 1: Fig. S3). Abnormal formation of intramolecular disulfide bonds in MSR-1 may lead to the failure to recognize free fipronil by $\mathrm{Nb}$-magnetosomes. Thereafter, Nb-magnetosomes biosynthesized by CFFF strain were chemically oxidized in vitro. The oxidization by $\mathrm{H}_{2} \mathrm{O}_{2}$ to form disulfide bond has been used in vitro and in vivo [36, 37]. It was reported that two reductive pathways (thioredoxin and glutaredoxin/glutathione) in the cytoplasm would be necessary for the engineering of $E$. coli to produce large quantity of cytoplasmic protein with disulfide bonds [38-42]. By using the thiotransferase glutaredoxin as a repair enzyme and glutathione as cofactor, the reducing potential of NADPH was employed to reduce glutathione via the glutathione oxidoreductase. 
Table 1 Average recoveries of fipronil from water samples as determined with $\mathrm{Nb}$-magnetosome-based ELISAs

\begin{tabular}{lll}
\hline Spiked level $(\mathbf{n g} / \mathbf{m L})$ & $\begin{array}{l}\text { Detected level }(\mathbf{n g} / \mathbf{m L}) \\
(\mathbf{m e a n} \pm \text { SD, } \mathbf{n = 3})\end{array}$ & $\begin{array}{l}\text { Average } \\
\text { recovery } \\
(\mathbf{C V}), \%\end{array}$ \\
\hline 0 & $<\mathrm{LOD}$ & \\
100 & $100.9 \pm 0.01$ & $101(1.6)$ \\
150 & $116.6 \pm 0.03$ & $78(8.1)$ \\
200 & $192.9 \pm 0.01$ & $96(5.4)$ \\
\hline
\end{tabular}

In the present study, the binding capability of $\mathrm{Nb}$ magnetosomes to free fipronil was increased after the oxidization by either $\mathrm{H}_{2} \mathrm{O}_{2}$ or the glutathione mixture consisting of GSH and GSSG. Although the sensitivity of the Nb-magnetosome-based ELISA was lower than that of the traditional $\mathrm{Nb}$-based ELISA available in our previous study [21], the former showed some advantages in the cost and assay time $(\sim 1 \mathrm{~h})$. The oxidized Nb-magnetosomes could be used for versatile applications such as in immunoassays, immunosensors, immunoprecipitation and immunoaffinity chromatography if reductive pathways in cytoplasm of MTB are engineered. It is likely that multiple technological improvements in magnetosome and nanobody engineering will improve incrementally with time making this technology more routine and widely applicable in immunochemical applications.

\section{Conclusions}

In this study, three mutant strains $\mathrm{CF}, \mathrm{CF}+$, and $\mathrm{CFFF}$ derived from MSR-1 were constructed by fusion PCR, producing novel functional MNPs consisting of antifipronil Nbs and magnetosomes. The Nb-magnetosomes biosynthesized by three mutant strains all recognized $\mathrm{H} 2-\mathrm{HRP}$ but not free fipronil. The Nb-magnetosomes from CFFF oxidized with $\mathrm{H}_{2} \mathrm{O}_{2}$ or GSH/GSSG in vitro have reasonable bind capacity to free fipronil, showing a promise to develop a MNP-based ELISA for the detection of fipronil in water. Furthermore, it was suggested that MTB could be used as a factory to cost-effectively produce eco-friendly $\mathrm{Nb}$-functionalized MNPs that have great prospect in the field of immunochemical science.

\section{Supplementary Information}

The online version contains supplementary material available at https://doi. org/10.1186/s12951-021-00773-z.

Additional file 1: Table S1. Bacteria strains and plasmids used in this study. Table S2. Primers used in this study. Fig. S1. The extraction and purification of Nb-magnetosomes. Fig. S2. The structures of fipronil and its hapten (H2). Fig. S3. The amino acid sequence of Nb F1.

\section{Acknowledgements}

This work was supported in part by the Key Project of Inter-Governmental International Scientific and Technological Innovation Cooperation (2019YFE0115800 and 2016YFE0108900), the Project of the National Natural Science Foundation of China (21577170 and 31570037), the Project for Extramural Scientists of State Key Laboratory of Agrobiotechnology (2020SKLAB65), the National Institute of Environmental Health Sciences (NIEHS) Superfund Research Program (P42ES04699), NIEHS RIVER Award (R35ES030443), and the USDA Hatch Project (HAW05044-R).

\section{Authors' contributions}

Designed the experiments: TX, JT, and SW. Executed the experiments: SW, FM, and JH; Analyzed the data: SW, FM, JH, QXL, BDH, JT and TX; Wrote the paper: SW, JT and TX. All authors read and approved the final manuscript.

\section{Competing interests}

The authors have declared that no competing interests exist. All data and materials are available and agreed to publish.

\section{Author details \\ ${ }^{1}$ Beijing Key Laboratory of Biodiversity and Organic Farming, College of Resources and Environmental Sciences, China Agricultural University, Bei- jing 100193, China. ${ }^{2}$ Suzhou Vicheck Biotechnology Co. Ltd, Suzhou 215128, China. ${ }^{3}$ Department of Molecular Biosciences and Bioengineering, Uni- versity of Hawaii At Manoa, 1955 East-West Road, Honolulu, HI 96822, USA. \\ ${ }^{4}$ Department of Entomology and Nematology and UCD Comprehensive Cancer Center, University of California, Davis, CA 95616, USA. ${ }^{5}$ Department of Microbiology, College of Biological Sciences, China Agricultural University, Beijing 100193, China.}

Received: 25 September 2020 Accepted: 8 January 2021

Published online: 19 January 2021

References

1. Chou Chau Y-F, Wang C-K, Shen L, Lim CM, Chiang H-P, Chou Chao C-T, Huang HJ, Lin C-T, Kumara NTRN, Voo NY. Simultaneous realization of high sensing sensitivity and tunability in plasmonic nanostructures arrays. Sci Rep. 2017;7(1):1-11.

2. Ranmadugala D, Ebrahiminezhad A, Manley-Harris M, Ghasemi Y, Berenjian A. Magnetic immobilization of bacteria using iron oxide nanoparticles. Biotechnol Lett. 2018;40(2):237-48.

3. Leon-Janampa N, Zimic M, Shinkaruk S, Quispe-Marcatoma J, Gutarra A, Le Bourdon G, Gayot M, Changanaqui K, Gilman RH, Fouquet E, Sheen P, Szlosek M. Synthesis, characterization and bio-functionalization of magnetic nanoparticles to improve the diagnosis of tuberculosis. Nanotechnology. 2020;31(17):175101.

4. Gopal J, Abdelhamid HN, Hua P-Y, Wu H-F. Chitosan nanomagnets for effective extraction and sensitive mass spectrometric detection of pathogenic bacterial endotoxin from human urine. J Mater Chem B. 2013;1(19):2463-75.

5. Abdelhamid HN, Wu H-F. Multifunctional graphene magnetic nanosheet decorated with chitosan for highly sensitive detection of pathogenic bacteria. J Mater Chem B. 2013;1(32):3950-61.

6. Lefevre CT, Bennet M, Landau L, Vach P, Pignol D, Bazylinski DA, Frankel RB, Klumpp S, Faivre D. Diversity of magneto-aerotactic behaviors and oxygen sensing mechanisms in cultured magnetotactic bacteria. Biophys J. 2014;107(2):527-38.

7. Uebe R, Schüler D. Magnetosome biogenesis in magnetotactic bacteria. Nat Rev Microbiol. 2016;14(10):621-37.

8. Ren E, Lei Z, Wang J, Zhang Y, Liu G. Magnetosome modification: from bio-nano engineering toward nanomedicine. Advanced Therapeutics. 2018;1(6):1800080.

9. Barber-Zucker S, Zarivach R. A Look into the biochemistry of magnetosome biosynthesis in magnetotactic bacteria. ACS Chem Biol. 2017;12(1):13-22.

10. Mickoleit F, Lanzloth C, Schüler D. A versatile toolkit for controllable and highly selective multifunctionalization of bacterial magnetic nanoparticles. Small. 2020;16(16):e1906922. 
11. Scheffel A, Gardes A, Grunberg K, Wanner G, Schüler D. The major magnetosome proteins MamGFDC are not essential for magnetite biomineralization in Magnetospirillum gryphiswaldense but regulate the size of magnetosome crystals. J Bacteriol. 2008;190(1):377-86.

12. Yoshino T, Matsunaga T. Efficient and stable display of functional proteins on bacterial magnetic particles using Mms13 as a novel anchor molecule. Appl Environ Microbiol. 2006;72(1):465-71.

13. Kanetsuki Y, Tanaka M, Tanaka T, Matsunaga T, Yoshino T. Effective expression of human proteins on bacterial magnetic particles in an anchor gene deletion mutant of Magnetospirillum magneticum AMB-1. Biochem Biophys Res Commun. 2012;426(1):7-11.

14. Xu J, Liu L, He J, Ma S, Li S, Wang Z, Xu T, Jiang W, Wen Y, Li Y, Tian J, Li F. Engineered magnetosomes fused to functional molecule (protein A) provide a highly effective alternative to commercial immunomagnetic beads. J Nanobiotechnol. 2019;17(1):37.

15. Goldman ER, Liu JL, Zabetakis D, Anderson GP. Enhancing stability of camelid and shark single domain antibodies: an overview. Front Immunol. 2017:8:865

16. Schumacher D, Helma J, Schneider AFL, Leonhardt H, Hackenberger CPR. Nanobodies: chemical functionalization strategies and intracellular applications. Angew Chem Int Ed Engl. 2018;57(9):2314-33.

17. Pollithy A, Romer T, Lang C, Muller FD, Helma J, Leonhardt H, Rothbauer U, Schüler D. Magnetosome expression of functional camelid antibody fragments (nanobodies) in Magnetospirillum gryphiswaldense. Appl Environ Microbiol. 2011;77(17):6165-71.

18. Bever CS, Dong JX, Vasylieva N, Barnych B, Cui Y, Xu ZL, Hammock BD, Gee SJ. VHH antibodies: emerging reagents for the analysis of environmental chemicals. Anal Bioanal Chem. 2016;408(22):5985-6002.

19. He J, Tian J, Xu J, Wang K, Li J, Gee SJ, Hammock BD, Li QX, Xu T. Strong and oriented conjugation of nanobodies onto magnetosomes for the development of a rapid immunomagnetic assay for the environmental detection of tetrabromobisphenol-A. Anal Bioanal Chem. 2018:410(25):6633-42.

20. He J, Ma S, Wu S, Xu J, Tian J, Li J, Gee SJ, Hammock BD, Li QX. XuT: Construction of immunomagnetic particles with high stability in stringent conditions by site-directed immobilization of multivalent nanobodies onto bacterial magnetic particles for the environmental detection of tetrabromobisphenol-A. Anal Chem. 2020;92(1):1114-21.

21. Wang K, Vasylieva N, Wan D, Eads DA, Yang J, Tretten T, Barnych B, Li J, Li QX, Gee SJ, Hammock BD, Xu T. Quantitative detection of fipronil and fipronil-sulfone in sera of black-tailed prairie dogs and rats after oral exposure to fipronil by camel single-domain antibody-based immunoassays. Anal Chem. 2019;91(2):1532-40.

22. El Hassani AK, Dacher M, Gauthier M, Armengaud C. Effects of sublethal doses of fipronil on the behavior of the honeybee (Apis mellifera). Pharmacol Biochem Behav. 2005;82(1):30-9.

23. Wright I. Fipronil: a microcosm of flea control? Companion Anim. 2013;18(4):139-41.

24. Shi L, Chen L, Wan Y, Zeng H, Xia W. Spatial variation of fipronil and its derivatives in tap water and ground water from China and the fate of them during drinking water treatment in Wuhan, central China. Chemosphere. 2020;251:126385.

25. Ali I, Peng C, Khan ZM, Naz I. Yield cultivation of magnetotactic bacteria and magnetosomes: a review. J Basic Microbiol. 2017;57(8):643-52.

26. Rong $C$, Huang $Y$, Zhang W, Jiang W, Li Y, Li J. Ferrous iron transport protein B gene (feoB1) plays an accessory role in magnetosome formation in Magnetospirillum gryphiswaldense strain MSR-1. Res Microbiol. 2008;159(7-8):530-6.

27. Zhang Y, Zhang XJ, Jiang W, Li Y, Li J. Semicontinuous culture of Magnetospirillum gryphiswaldense MSR-1 cells in an autofermentor by nutrientbalanced and isosmotic feeding strategies. Appl Environ Microbiol. 2011;77(17):5851-6.

28. Wang Q, Liu JX, Zhang WJ, Zhang TW, Yang J, Li Y. Expression patterns of key iron and oxygen metabolism genes during magnetosome formation in Magnetospirillum gryphiswaldense MSR-1. FEMS Microbiol Lett. 2013;347(2):163-72.

29. Schneider P, Hammock BD. Influence of the ELISA format and the hapten-enzyme conjugate on the sensitivity of an immunoassay for
S-triazine herbicides using monoclonal antibodies. J Agric Food Chem. 2002;40(3):525-30.

30. Grant CR, Rahn-Lee L, LeGault KN, Komeili A. Genome editing method for the anaerobic magnetotactic bacterium Desulfovibrio magneticus RS-1. Appl Environ Microbiol. 2018;84(22):e01724-e1818.

31. Wang $X$, Wang $Q$, Zhang W, Wang Y, Li L, Wen T, Zhang T, Zhang Y, Xu J, Hu J, Li S, Liu L, Liu J, Jiang W, Tian J, Li Y, Schüler D, Wang L, Li J. Complete genome sequence of Magnetospirillum gryphiswaldense MSR-1. Genome Announc. 2014. https://doi.org/10.1128/genomeA.00171-14.

32. Scheffel A, Gruska M, Faivre D, Linaroudis A, Plitzko JM, Schüler D. An acidic protein aligns magnetosomes along a filamentous structure in magnetotactic bacteria. Nature. 2006;440(7080):110-4.

33. Wang $X$, Zheng H, Wang $Q$, Jiang W, Wen Y, Tian J, Sun J, Li Y, Li J. Novel protein Mg2046 regulates magnetosome synthesis in Magnetospirillum gryphiswaldense MSR-1 by modulating a proper redox status. Front Microbiol. 2019;10:1478.

34. Eggenreich B, Willim M, Wurm DJ, Herwig C, Spadiut O. Production strategies for active heme-containing peroxidases from $E$. coli inclusion bodies - a review. Biotechnol Rep (Amst). 2016;10:75-83.

35. Carroll L, Jiang S, Irnstorfer J, Beneyto S, Ignasiak MT, Rasmussen LM, Rogowska-Wrzesinska A, Davies MJ. Oxidant-induced glutathionylation at protein disulfide bonds. Free Radic Biol Med. 2020;160:513-25.

36. Karala AR, Lappi AK, Saaranen MJ, Ruddock LW. Efficient peroxide-mediated oxidative refolding of a protein at physiological $\mathrm{pH}$ and implications for oxidative folding in the endoplasmic reticulum. Antioxid Redox Signal. 2009;11(5):963-70.

37. Margittai E, Low P, Stiller I, Greco A, Garcia-Manteiga JM, Pengo N, Benedetti A, Sitia R, Banhegyi G. Production of $\mathrm{H}_{2} \mathrm{O}_{2}$ in the endoplasmic reticulum promotes in vivo disulfide bond formation. Antioxid Redox Signal. 2012;16(10):1088-99.

38. Lobstein J, Emrich CA, Jeans C, Faulkner M, Riggs P, Berkmen M. SHuffle, a novel Escherichia coli protein expression strain capable of correctly folding disulfide bonded proteins in its cytoplasm. Microb Cell Fact. 2012;11(1):56-71.

39. Derman Al, Prinz WA, Belin D, Beckwith J. Mutations that allow disulfide bond formation in the cytoplasm of Escherichia coli. Science. 1993;262:1744-7.

40. Stewart EJ, Aslund F, Beckwith J. Disulfide bond formation in the Escherichia coli cytoplasm: an in vivo role reversal for the thioredoxins. EMBO J. 1998;17(19):5543-50.

41. Ritz D, Lim J, Reynolds CM, Poole LB, Beckwith J. Conversion of a peroxiredoxin into a disulfide reductase by a triplet repeat expansion. Science. 2001;294(5540):158-60.

42. Bessette PH, Aslund F, Beckwith J, Georgiou G. Efficient folding of proteins with multiple disulfide bonds in the Escherichia coli cytoplasm. Proc Natl Acad Sci U S A. 1999;96:13703-8.

\section{Publisher's Note}

Springer Nature remains neutral with regard to jurisdictional claims in published maps and institutional affiliations.

\footnotetext{
Ready to submit your research? Choose BMC and benefit from:

- fast, convenient online submission

- thorough peer review by experienced researchers in your field

- rapid publication on acceptance

- support for research data, including large and complex data types

- gold Open Access which fosters wider collaboration and increased citations

- maximum visibility for your research: over 100M website views per year
}

At BMC, research is always in progress.

Learn more biomedcentral.com/submissions 